\title{
Formation of intellectual and pedagogical competence of postgraduates in the conditions of a steadily developing innovative educational environment
}

\author{
A.V. Kachalov ${ }^{1,}{ }^{*}$, D.V. Kachalov ${ }^{1}$, L.P. Kachalova ${ }^{2}, I . V$. Kolmogorova $^{2}$, and T.A. \\ Kolosovskaya ${ }^{2}$ \\ ${ }^{1}$ Ural State University of Railway Transport, Russia, Yekaterinburg \\ ${ }^{2}$ Shadrinsk State Pedagogical University, Russia, Shadrinsk
}

\begin{abstract}
The article substantiates the need for the formation of the intellectual and pedagogical competence of postgraduates of future university teachers in the conditions of a sustainable innovative educational environment. The essential characteristic of intellectual and pedagogical competence, its components, including the ability to apply the acquired knowledge for the effective implementation of the process of teaching and upbringing of students, the ability to innovative pedagogical activity are revealed. The relevance of the problem of the formation of this competence at the scientific and pedagogical level is due to the need to select the content of educational disciplines of the pedagogical cycle, based on the requirements of the professional activity of a teacher, a teacherresearcher with a focus to new social demands, that determine the goals of sustainable development of higher education. In a professionally oriented aspect, the formation of the intellectual and pedagogical competence of postgraduates is directly dependent on the ability to implement educational programs, to apply modern technologies and methods of teaching and educating students, on the readiness for pedagogical activity as a teacher, teacher-researcher, which entails the need to master intellectual and pedagogical knowledge and skills, projected on the solution of professional tasks, that constantly arise in the educational process.
\end{abstract}

\section{Introduction}

The requirements of modern society set new requirements for the organization of postgraduate study, as the level of training of personnel of higher scientific qualifications and, which is one of the levels of higher education, which plays the role of the main channel for completing scientific and pedagogical personnel for sustainable development of the university.

Among the necessarily formed competencies of postgraduate students (the ability for critical analysis, generating new ideas, when solving research and practical problems; the

\footnotetext{
*Corresponding author: screamer-78@mail.ru
} 
ability to design and carry out comprehensive research; willingness to participate in the work of Russian and international research teams to solve scientific and scientific and educational problems; willingness to use modern methods and technology of scientific communication in native and foreign languages; the ability to make independent motivated decisions in non-standard situations and the willingness to bear responsibility for their consequences) $[1 ; 2,-$ p. 80-86], attention is focused on the formation of intellectual and pedagogical competence.

The formation of intellectual and pedagogical competence is determined by one of the priority goals of higher education at the level of training personnel of higher scientific qualifications ("teacher. teacher-researcher"), possessing the characteristics of competitiveness, self-education, self-realization, the ability to analyze and solve the assigned tasks, aiming for personal and professional growth, specialists with a high level of intellectual and pedagogical competence.

There is a rather different approach to the definition of the concept of "intellectual and pedagogical competence" in research, but in general, it combines two components at its root: "intellect" and "competence", which have the ability to sum them up as "intellectual and pedagogical competence".

Despite the fact, that this concept is used in the scientific literature, there is currently no single definition. More often this is a differentiated interpretation through emphasizing the "intellectual" component of the pedagogical competence. At the same time, it should be noted, that the generalization and synthesis of the concepts of "competence" and "intelligence", considered as "the unity of logical methods of mental activity, intellectual abilities, creativity and the ability to self-education and self-improvement", give a new sense and are designated as intellectual competence.

Here are some definitions, that exist in scientific research.

Dividing intellectual and pedagogical, scientists give the following definition: intellectual competence is the ability to think analytically and implement an integrated approach to performing one's duties; intellectual and pedagogical competence is considered as a complex of skills for analysis, synthesis, comparison, abstraction, generalization, concretization, fantasy, flexibility and critical thinking. [3 No. 4 - P. 41; 5 - P. 51-55]

Intellectual and pedagogical competence is expressed in the ability to apply existing knowledge to establish pedagogically expedient interrelations, the acquisition and transformation of knowledge by students and the teacher himself, as well as to develop ways of innovation activity. [6].

Intellectual and pedagogical competence in research in the context of professional pedagogical is defined as the teacher's ability to perform mental operations, the subject of which is pedagogical objects (concepts, phenomena, processes); possession of the necessary pedagogical objects - knowledge and experience, and also requires a sufficient level of intelligence [7].

Intellectual and pedagogical competence is also defined as the qualities of intelligence: flexibility, fantasy, analogy, critical thinking, as a set of skills to analyze, synthesize, compare, abstract, generalize, concretize. A teacher with such competence effectively conducts pedagogical research, knows, how to build a program of his own professional development, identify difficulties, that hamper this development, and constantly learns himself [8, p. 14-17].

Researchers pay attention to the level and structural composition of intellectual and pedagogical competence and highlight the following components in it:

- analytical-synthetic (insight into the essence of the phenomenon under consideration);

- comparison as a definition of similarity and difference in the compared phenomena, subjects, objects;

- abstraction (modeling of an abstract subject); 
- generalization and concretization, analogies, fantasy, critical thinking.

The levels are highlighted in the following form: the level of subject-specific knowledge and practical skills and the universal level.

Universal signs of intellectual competence are the formation of metacognitive experience and unintentional intellectual control [9, P. 29].

The analysis of the above characteristics and definitions of intellectual and pedagogical competence allows to consider it as a complex logical integral quality, that synthesizes professional and personal qualities, including the ability to think analytically, analytical skills, the ability to compare, abstract, generalize, critical thinking, ensuring the effectiveness of pedagogical activity. Important indicators are the ability to perform operations of mental activity, in particular to analyze, compare, highlight the essential, synthesize, prove (establish) cause-effect relations, show the ability to generalize, prove, construct hypothesis, critical thinking.

\section{Materials and Methods}

The formation of the intellectual and pedagogical competence of postgraduates was carried out in the course of a pedagogical experiment in the process of training personnel of higher scientific qualifications (postgraduates) in the conditions of sustainable development of the innovative educational environment of the university.

By a sustainable (developing) innovative educational environment, we mean an environment, that has a number of features:

- search mode through the development and introduction of pedagogical technologies;

- constant updating of the content of the educational program;

- involvement of subjects of education in active search and creative innovation and development activity;

- zoning of activity through the projection of the activities of postgraduates of an intellectual-creative, intellectual-research, intellectual-search nature.

The unique innovative state of the educational environment of the university gives it the meaning of sustainable developmental education, and this is one of the main steps, that afford an opportunity for the student to develop his abilities, to adequately master professional (in our case, intellectual and pedagogical) competencies.

In light of this, the intellectual and pedagogical competence, formed in the innovative mode of education, "largely determines the mobility of the personality and contributes to its self-realization" [10, P. 18] [.

Formation of intellectual and pedagogical competence of postgraduates in innovative educational developing environment of the university should be perceived as a unity of the theoretical and practical readiness and ability of the individual to carry out the activity of a teacher, teacher-researcher, taking into account the innovative transformations of education, based on the construction of a didactic system, which involves the priority use of technologies for the intellectual development of postgraduates "invested in the form of the corresponding didactic material" [11, P. 75].

The model representation of an innovative developing educational environment is represented by process characteristics and includes:

- the target component in the dual unity of content - the formation of the intellectual and pedagogical competence of postgraduates and the development of an innovative educational environment as a tool for a sustainable educational space of the university;

- the content component of the model of the innovative educational environment is filled with the content of the program for the formation of the intellectual and pedagogical competence of postgraduates, in the logical construct of which theoretical, practical, intellectually developing sections are introduced; 
- the procedural component of the model of the innovative educational environment of the university is projected onto the formation of the constituent indicators of the intellectual and pedagogical competence of postgraduates; its implementation is carried out through the introduction of lecture-practical, practice-oriented forms of teaching, active teaching methods, active and interactive forms of organizing classes;

- the zonal component of the model of an innovative educational environment provides for the zoning of the activity of postgraduates, which is associated with the activity of the teacher. teacher-researcher;

- the final control component has an analytical function, aimed at identifying the formed level of intellectual and pedagogical competence of postgraduates.

The innovative educational environment as a steadily developing mechanism of the university in the process of forming the intellectual and pedagogical competence of postgraduates provides for the zoning of activities, related to the solution of intellectual and pedagogical professional tasks. The main zones are the design and research, intellectual and didactic, scientific and research, practice-oriented creative zone.

In each zone, the content of the activity of postgraduates is determined.

The design and research zone provides for the involvement of postgraduates in the structuring of scientific and qualification work, during which it is mandatory to work out and understand, formulate goals and tasks, principles for selecting methods and techniques, planning the course of research, determining expected results, and determining the necessary resources.

The design and research activity of postgraduates provide for the solution of a creative scientific and research problem. So, in the course of developing a project of scientific and qualification work, postgraduates determine the stages of research, give them essential characteristics, determine the problem of research at the socio-pedagogical, scientificpedagogical and technological levels. Collection of own material, its analysis are subject to public discussion.

The intellectual and didactic zone includes the organization of intellectual and didactic games, competitions, discourses, methodological discussions, immersion seminars.

In this term, postgraduates are involved in perceptual modeling of classes, interaction with students, solving conflict situations, developing cycles of immersion seminars, thematic plans for conducting practice-oriented seminars with students, selection of the content of didactic materials for the introduction of active forms of educational activity of students, develop problem-based game technologies for teaching students, carry out didactic experimentation.

The scientific and research zone is associated with the acquisition of experience in the research of an urgent scientific problem, which is the subject of scientific and qualification work, the development of the ability to independently carry out research activity, associated with solving complex professional problems in innovative conditions.

Organizational forms in the context of this zone: approbation of scientific research results: participation in scientific conferences, symposia; speeches at the staff meetings; preparation and proposals for the use of research results; publication activity based on research results.

A practice-oriented creative zone determines activity, aimed at the formation of knowledge and skills, that can be implemented to solve practical problems within the framework of professional activity in innovative conditions. Postgraduates develop practice-oriented projects, project its prospects, simulate fragments of the teacher's professional activity, focus on joint activity with students to develop a subject project, and others.

Projects (creative, practice-oriented, research, didactic-teaching, social-pedagogical and others) are functionally accompanied by algorithmic prescriptions at the initial stage, and in 
the future they require an independent reflexive analysis of the difficulties, that arise, the implementation of criticism to identify the causes of difficulties, which ensures the development of analytical logic and skills to meaningfully solve emerging logical gaps in the developed project.

Each zone of the innovative educational environment provides for the inclusion of postgraduates in various types of intellectual and pedagogical creative research activities, aimed at enhancing cognitive, project, intellectual and research activities. For this, the combined state of the zones of the innovative educational environment includes pedagogical creative laboratories, scientific communities of postgraduates and teachers, interested in mutual creativity, study, development, generalization of materials on the stated topic in order to find optimal ways of developing the topic under study for direct practical activity, mobilizing the creative potential of postgraduates and teachers. The results of the participation of students' work in creative laboratories are presented at research competitions, research to practice conferences. [12]

\section{Results and Discussion}

In the course of the research, the priority characteristics of the process of forming the intellectual and pedagogical competence of postgraduates was their transition to the position of theoretical thinking, logic and comprehension of their own design and research, didactic and intellectual, scientific and research, practice-oriented, creative activity; the ability was formed to transform scientific methods, methods of formal logic into a specific scientific and methodological system, into a system of methods and techniques of mental activity; application of logical forms, laws in the process of solving intellectual and pedagogical problems of a professional direction in the innovative educational environment of a university.

In the activities of the scientific and research direction, it contributes to the formation of not only the experience of research activity, but also the ability to substantiate existing differences in concepts and thoughts, highlight the problem and find ways to solve it.

The intellectual and didactic zone determined the direction of the dynamics in terms of intellectual and pedagogical competence: fluent in the logical and intellectual content of educational situations, scientific problems, didactic problems, the ability to find and identify techniques and methods for solving a didactic problem.

a practice-oriented zone of an innovative educational environment created conditions for factual persuasion and judgment of practice-oriented tasks.

At the end of the pedagogical experiment, $76 \%$ of postgraduates at a high level formed indicators of intellectual and pedagogical competence, expressed in the ability to logically and meaningfully comprehend professional and pedagogical tasks, to model, abstract and predict the tasks to be solved in the format of professional activity.

The formation of the intellectual and pedagogical competence of postgraduates is indicated by such indicators as: the ability to think analytically $(69 \%)$, the ability to analyze, synthesize, compare, abstract $(74 \%)$, meaningfully generalize phenomena, facts (79\%), indicators of concretization, fantasy, flexibility and critical thinking are formed. The analysis of the results at the final stage of the pedagogical experiment showed a steady trend to a significant improvement in the indicators of the intellectual and pedagogical competence of postgraduates. 


\section{Conclusion}

On the basis of theoretical analysis, it is shown, that the intellectual and pedagogical competence of postgraduates is a complex integrative personality quality, a stable personality education, expressing the ability to analyze, deeply comprehend, critically think and project them into the format of professional pedagogical activity.

Considering the process of forming the intellectual and pedagogical competence of postgraduates, the necessity and significance of the implementation of this process in an innovative educational environment with the characteristics of sustainable development is determined. The proposed model of an innovative developing educational environment confirmed its effectiveness in solving the problem of forming the intellectual and pedagogical competence of postgraduates.

The formation of the intellectual and pedagogical competence of postgraduates in a steadily developing innovative educational environment is carried out on the basis of: the unity of the formation of logical and professional pedagogical thinking; intellectual and didactic content filling of the zones of the innovative educational environment; the unity of the formation of formal, dialectical logic and intellectually logical tasks among postgraduates; subordination of the formation of intellectual and pedagogical competence of postgraduates to the specifics of their future professional activity.

\section{References}

1. I.A. Zimnyaya, Higher education today, 5 (2013)

2. A.V. Zolotareva, Yaroslavl Pedagogical Bulletin, 3, 80 (2009)

3. V.N. Vvedensky, Intellectual and pedagogical competence: educational book, 120 (2003)

4. V.N. Vvedensky, Alma Mater, 2, 41 (2013)

5. V.N. Vvedensky, Pedagogy, 10, 51 (2003)

6. J. Raven, Competence in modern society: identification, development and implementation (2002)

7. E.F. Zeer, Psychology of professions: Educational book for university students, 336 (2003)

8. S.N. Chistyakova, Professional education. Stolitsa, 4, 14 (2013)

9. M.A. Kholodnaya, Psychological journal, 1, 29 (2005)

10. S.I. Novikov, Social mobility of university graduates in the conditions of modernization of Russian society, 18 (2005)

11. E.E. Polyanskaya, Bulletin of the South Ural State Humanitarian and Pedagogical University, 6(159), 74 (2020)

12. Ludmila Pavlovna Kachalova, Irina Vladimirovna Kolmogorova, Tatyana Aleksandrovna Kolosovskaya, Lubov Gennadyevna Svetonosova, Larisa Valeryevna Solonina, International Journal of Innovative Technology and Exploring Engineering (IJITEE), 8(8) (2019) 